\title{
Effects of different resistance training frequencies on flexibility in older women
}

\author{
This article was published in the following Dove Press journal: \\ Clinical Interventions in Aging \\ 5 March 2015 \\ Number of times this article has been viewed
}

\author{
Nelson H Carneiro ${ }^{1,2}$ \\ Alex S Ribeiro' \\ Matheus A Nascimento' \\ Luís A Gobbo 3 \\ Brad J Schoenfeld ${ }^{4}$ \\ Abdallah Achour Júnior' \\ Sebastião Gobbi ${ }^{5}$ \\ Arli R Oliveira' \\ Edilson S Cyrino' \\ 'Study and Research Group in \\ Metabolism, Nutrition, and Exercise, \\ Physical Education Department, \\ Londrina State University, Londrina, \\ ${ }^{2}$ Physical Education Department, \\ Oeste Paulista University, Presidente \\ Prudente, ${ }^{3}$ Universidade Estadual \\ Paulista, UNESP, Faculdade de Ciência e \\ Tecnologia/Departamento de Educação \\ Física, Presidente Prudente, Brazil; \\ ${ }^{4}$ Exercise Science Department, The \\ City University of New York Lehman \\ College, Bronx, New York, USA; \\ 5Universidade Estadual Paulista, UNESP, \\ Institudo de Biociências/Departamento \\ de Educação Física, Laboratory of \\ Aging and Physical Activity (LAFE), \\ Rio Carlo, São Paulo, Brazil
}

Correspondence: Edilson S Cyrino Universidade Estadual de Londrina, Celso Garcia Cid highway, km 380 - University Campus, Zip code 8605I-990, Londrina PR, Brasil

Email emcyrino@uel.br
Objective: The main purpose of the investigation reported here was to analyze the effect of resistance training (RT) performed at different weekly frequencies on flexibility in older women.

Participants and methods: Fifty-three older women ( $\geq 60$ years old) were randomly assigned to perform RT either two ( $n=28$; group "G2x"), or three ( $n=25$; group "G3x") times per week. The RT program comprised eight exercises in which the participants performed one set of 10-15 repetitions maximum for a period of 12 weeks. Anthropometric, body-composition, and flexibility measurements were made at baseline and post-study. The flexibility measurements were obtained by a fleximeter.

Results: A significant group-by-time interaction $(P<0.01)$ was observed for frontal hip flexion, in which G3x showed a higher increase than $\mathrm{G} 2 \mathrm{x}(+12.8 \%$ and $+3.0 \%$, respectively). Both groups increased flexibility in cervical extension ( $\mathrm{G} 2 \mathrm{x}=+19.1 \%, \mathrm{G} 3 \mathrm{x}=+20.0 \%)$, right hip flexion $(\mathrm{G} 2 \mathrm{x}=+14.6 \%, \mathrm{G} 3 \mathrm{x}=+15.9 \%)$, and left hip flexion $(\mathrm{G} 2 \mathrm{x}=+25.7 \%$, G3 $\mathrm{x}=+19.2 \%)$, with no statistical difference between groups. No statistically significant differences were noted for the increase in skeletal muscle mass between training three versus two times a week $(+7.4 \%$ vs $+4.4 \%$, respectively).

Conclusion: Twelve weeks of RT improves the flexibility of different joint movements in older women, and the higher frequency induces greater increases for frontal hip flexion.

Keywords: elderly, muscle mass, physical fitness, range of motion, strength training

\section{Introduction}

Aging is associated with changes in various body systems including in the neuromuscular structures, which lead to a reduction in important components of physical fitness. ${ }^{1}$ The preservation of fitness-related components such as muscular strength, endurance, and flexibility are essential to the performance of daily activities, which thus helps to maintain autonomy and quality of life in the elderly population..$^{2-5}$ Of these fitness-related components, flexibility is often less appreciated with respect to its contribution to optimal health and functional status as well as independent living for the elderly. ${ }^{3,6}$ Flexibility reductions may increase the risks of injury, falling, back pain, and physical dependence in older adults. ${ }^{7}$

Several mechanisms have been proposed for reductions in flexibility, among them alterations in soft-tissue structures and physical inactivity. ${ }^{7}$ When a joint is relatively inactive due to sedentary behavior, the muscles that cross it shorten, thereby reducing its range of motion. Moreover, independent of activity levels, the aging process plays a role in flexibility decreases. ${ }^{8}$ Joint structures such cartilage, ligaments, and tendons change mechanically and biochemically with aging, increasing muscular and tendon stiffness and thus impeding mobility. ${ }^{9-11}$ On the other hand, maintaining 
a physically active lifestyle may result in improvement of functional performance with advancing age, thus enabling the execution of activities of daily living with more vigor and less fatigue. ${ }^{12,13}$

While resistance training (RT) is recommended for older people for the development of muscular strength, ${ }^{13,14}$ some studies have indicated that regular participation in RT programs may also contribute to increased flexibility. ${ }^{11,15-19}$ In fact, there is evidence that regular RT serves as an active form of flexibility training and can improve range of motion to a similar extent as typical static stretching protocols. ${ }^{20}$ Regular performance of RT may improve flexibility by reducing passive tension and stiffness of the tissues surrounding a joint. ${ }^{11}$ Thus, from a time-saving standpoint, RT is a good way to develop both strength and flexibility as well as achieve improvements in body composition within a single session of training.

The fitness-related benefits associated with RT are dependent on the manipulation of variables such as intensity, volume, exercise order, and rest intervals. ${ }^{12}$ With respect to training volume, manipulation can involve varying the number of repetitions, sets, and/or "frequency" - defined here as the number of sessions performed per week. The American College of Sports Medicine recommends that older adults engage in two to three RT sessions a week for improving neuromuscular fitness. ${ }^{12}$ However, there is a current paucity of research regarding the effects of different RT weekly frequencies on flexibility adaptive responses. Previous studies are limited to analyzing the impact of RT on flexibility without regard for manipulation of the variables that make up the training program. Considering the importance of flexibility in the health and wellness of the elderly, such information is of great importance when prescribing RT programs in this population.

Therefore, the main purpose of this investigation was to analyze the effect of RT performed at different weekly frequencies on flexibility in untrained older women. We hypothesized that higher RT frequencies would result in greater flexibility increases than lower frequencies. The rational for our hypothesis is based on a dose-response relationship between training volume and muscle strength and hypertrophy, ${ }^{21,22}$ whereby greater training volumes are associated with enhanced muscular adaptations. We speculated that flexibility increases would have a similar dose-response relationship. A secondary aim of the study was to assess RT frequency-related changes in skeletal muscle mass. In accordance with the aforementioned dose-response relationship, it was hypothesized that muscle protein accretion would be greater with the higher frequency program.

\section{Methods \\ Participants}

Recruitment of the participants was carried out through newspaper and radio advertisements and home delivery of flyers in Londrina, Paraná, Brazil. A total of 350 older women responded to the advertisements, and then completed detailed health history and physical activity questionnaires. The women were subsequently admitted to the study if they met the following inclusion criteria: non-hypertensive (systolic blood pressure $<140 \mathrm{mmHg}$ and diastolic blood pressure $<90 \mathrm{mmHg}$ ), nondiabetic, free from cardiac or renal dysfunction, nonsmoking, not receiving hormonal replacement therapy, not performing any regular physical exercise more than once per week over the preceding 6 months, and participated in $>85 \%$ of the study training sessions.

Of the 350, 286 subjects were not selected for participation in the study. The remaining 64 older women ( $\geq 60$ years old) were randomly assigned to one of two groups: a group that performed RT two times per week $(\mathrm{n}=32$; group "G2x") or a group that performed RT three times per week ( $\mathrm{n}=32$; group "G3x"). A total of 53 women $(\mathrm{G} 2 \mathrm{x}=28 ; \mathrm{G} 3 \mathrm{x}=25)$ completed the study and therefore were included in the analysis. Reasons for the eleven dropouts included insufficient attendance to training sessions and voluntary abandonment. Participants passed a diagnostic, graded exercise stress test with twelve-lead electrocardiography reviewed by a cardiologist and were released with no restrictions for participation in this study.

Written informed consent was obtained from all subjects. This investigation was conducted according to the Declaration of Helsinki, and was approved by the Londrina State University ethics committee. Figure 1 is a schematic representation of participant recruitment and allocation.

\section{Experimental design}

The study was carried out over a period of 16 weeks, with 12 weeks dedicated to the RT program and 4 weeks used for testing. Anthropometric, body-composition, and flexibility measurements were performed at Weeks 1-2 and 15-16 for baseline and post-training analysis, respectively, while the supervised RT program was performed during Weeks 3-14. Trained fitness personnel supervised all sessions. Subjects were instructed not to perform any other type of physical exercise during the entire study period. 


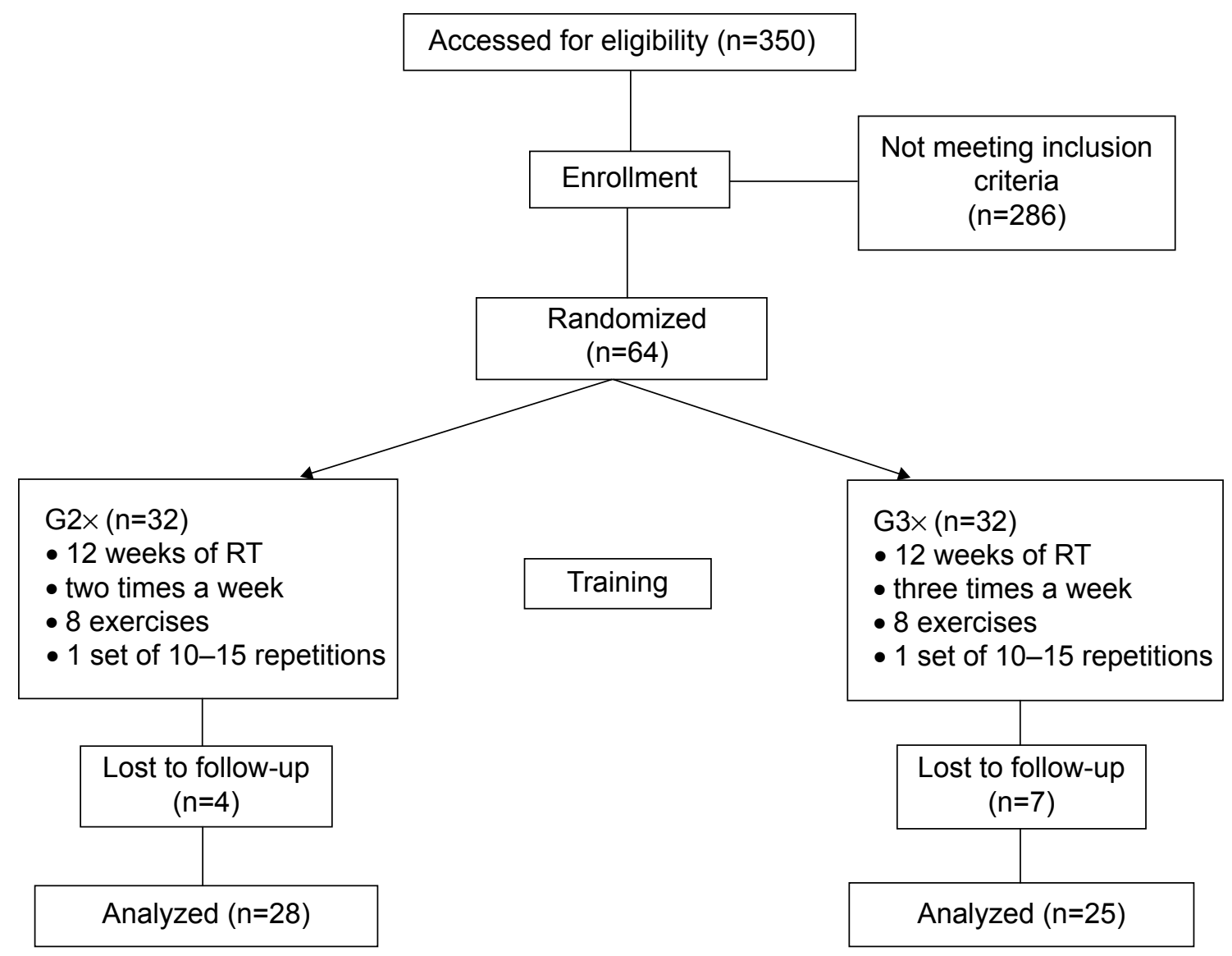

Figure I Schematic representation of participant recruitment and allocation. Abbreviation: $\mathrm{RT}$, resistance training.

\section{Anthropometry}

Body mass was measured to the nearest $0.1 \mathrm{~kg}$ using a calibrated electronic scale (Balmak scale, model III, São Paulo, Brazil), with the participants wearing light workout clothing and no shoes. Height was measured with a stadiometer attached on the scale to the nearest $0.1 \mathrm{~cm}$ with subjects standing without shoes. Body mass index was calculated as body mass in kilograms divided by the square root of height in meters.

\section{Body composition}

The skeletal muscle mass was estimated by the predictive equation proposed by Kim et al. ${ }^{23}$ The appendicular fatfree mass used in the equation was determined by a dual energy X-ray absorptiometry scan (Lunar Prodigy NRL 41990, GE Lunar, Madison, WI, USA). Before scanning, participants were instructed to remove from their person all objects containing metal. Scans were performed with the subjects lying in the supine position along the table's longitudinal centerline axis. Feet were taped together at the toes to immobilize the legs, while the hands were maintained in a pronated position within the scanning region. Subjects remained motionless during the entire scanning procedure. Both calibration and analysis were carried out by a skilled laboratory technician. The equipment calibration followed the manufacturer's recommendations. The software generated standard lines that set apart the limbs from the trunk and head. These lines were adjusted by the same technician using specific anatomical points determined by the manufacturer. Analyses during the intervention were performed by the same technician who was blinded to intervention time point. Previous test-retest scans resulted in a standard error of measurement of $0.29 \mathrm{~kg}$ and intra-class correlation coefficient of 0.997 for skeletal muscle mass.

\section{Flexibility measurements}

To evaluate a subject's flexibility, five joint movements were adopted: cervical flexion (CF), cervical extension (CE), frontal hip flexion (FHF), left hip flexion, and right hip flexion. These movements were chosen because the flexibility of the hip and cervical spine are highly important for the elderly, especially for locomotion, eye orientation, and good timeline 
perception. ${ }^{24}$ All measurements were obtained by a fleximeter (Code, American do Brazil Ltda, São Paulo, Brazil) with a degree scale. All the procedures were made according to procedures and recommendations described elsewhere. ${ }^{25}$ Briefly, in both CF and CE subjects remained lying supine on a stretching table in order to neutralize any possible compensatory movements, and the fleximeter was positioned at the side of the head, in the sagittal plane, starting with $\mathrm{CF}$, where they moved the head slowly, until the chin leaned on the sternum or noticed a rigidity in the final range of motion; for CE, the subjects moved their head back slowly. For FHF, the fleximeter was positioned next to the hip just above the iliac crest, in a standing position with shoulders vertically flexed, elbows extended, fingers intertwined, legs together, then the subjects flexed frontally the hip, with knees extended throughout the movement. For lateral hip flexion, the fleximeter was placed on the medial surface of the thoracic spine, the participant remained standing, with legs together, and knees extended, but with arms crossing the trunk and hands on the contrary shoulder, and then performed the lateral trunk flexion, as a special consideration to such movement, the heel should remain supported on the ground. For all moves, after fixing the Velcro attached to the fleximeter and setting the zero point, the participants executed the movements as far as they could or until tightness or discomfort in the final range of motion was felt, and at the end range of motion the evaluator recorded the measure - at this point the participants were instructed to remain in the final position until the reading was completed. The highest score obtained from the three measurements at each joint motion was adopted as a reference standard. Three measurements were obtained for each joint movement without any warm-up.

The same evaluator made the measurements at baseline and after 12 weeks of intervention. The information obtained at baseline was not made available to the evaluator at the time of revaluation in an attempt to avoid their unduly influencing the results. It is worth emphasizing that the evaluator had over 2 years' experience, and based on the test-retest, the standard error of measurement and the intra-class correlation coefficient among the movements were $\leq 2.26$ degrees and $\geq 0.950$, respectively, and the maximal technical error among the movements analyzed was 1.19 degrees.

\section{Training load}

During the intervention period, in each session, the instructors registered the load $(\mathrm{kg})$ for each of the eight exercises for all the subjects. Afterwards, training load for each subject was weekly calculated, using the sum of the load employed in the exercises as a reference for each week.

\section{Resistance-training program}

Supervised RT was carried out for 12 weeks during the morning hours, in the Londrina State University facilities. The protocol was based on recommendations for RT in an older population to improve muscular endurance and strength. ${ }^{12,13}$ All participants were personally supervised by physical-education professionals with substantial RT experience to help ensure consistent and safe performance. Subjects performed RT using a combination of free weights and machines.

G2x performed two RT sessions per week on Tuesdays and Thursdays, while G3x performed the same exercises in three sessions per week on Mondays, Wednesdays, and Fridays. The RT program was a whole-body program with eight exercises comprising one exercise with free weights and seven with machines, performed exactly in the following order: chest press, horizontal leg press, seated row, knee extension, preacher curl (free weights), leg curl, triceps pushdown, and seated calf raise. Participants performed one set of 10-15 repetitions maximum. Participants were instructed to inhale during the eccentric phase and exhale during the concentric phase while maintaining a constant velocity of movement at a ratio of approximately 1:2 seconds (concentric and eccentric phases, respectively). Participants had 2 to 3 minutes' rest between each exercise. Instructors adjusted the loads of each exercise according to the subject's ability and improvements in exercise capacity throughout the study in order to ensure that the subjects were exercising with as much resistance as possible while maintaining proper exercise technique. Progression was planned so that when 15 repetitions were completed for two consecutive training sessions, weight was increased $2 \%-5 \%$ for the upper limb exercises and 5\%-10\% for the lower limb exercises in the next session. ${ }^{12}$ It is important to note that the participants did not perform any type of warm-up or cool-down exercises at the beginning or end of the session, respectively.

\section{Statistical analyses}

Normality was checked by the Shapiro-Wilk's test. The data were expressed as mean and standard deviation. Levene's test was used to analyze the homogeneity of variances. Two-way analysis of variance for repeated measures was used for within-group comparisons. In variables where sphericity was violated, as indicated by Mauchly's test, the analyses were adjusted using a Greenhouse-Geisser correction. When the $F$-ratio was significant, Bonferroni's 
Table I General characteristics of the sample at baseline. Data are expressed as mean and standard deviation

\begin{tabular}{|c|c|c|c|}
\hline Variable & G2x $(n=28)$ & G3x $(n=25)$ & $P$-value \\
\hline Age (years) & $67.6 \pm 5.3$ & $67.0 \pm 5.6$ & 0.71 \\
\hline Body mass (kg) & $70.3 \pm 14.2$ & $70.5 \pm 14.7$ & 0.95 \\
\hline Height $(\mathrm{cm})$ & $155.6 \pm 5.6$ & $157.3 \pm 7.5$ & 0.24 \\
\hline Body mass index $\left(\mathrm{kg} / \mathrm{m}^{2}\right)$ & $29.0 \pm 5.1$ & $28.3 \pm 5.0$ & 0.63 \\
\hline
\end{tabular}

Notes: G2x, group that performed resistance training two times per week; G3x, group that performed resistance training three times per week.

post-hoc test was employed to identify the mean differences. Baseline differences between groups were explored with an independent $t$-test. The effect size (ES) was calculated to verify the magnitude of the differences by Cohen's d, where an ES of 0.20-0.40 was considered small, 0.50-0.79 as moderate, and $\geq 0.80$ as large.$^{26}$ For all statistical analyses, significance was accepted at $P<0.05$. The data were stored and analyzed using STATISTICA software (v 10.0; StatSoft Inc, Tulsa, OK, USA).

\section{Results}

Table 1 displays the general characteristics of the participants at baseline. No significant differences were observed between groups $(P>0.05)$.

Figure 2 shows the total weekly training load during the experiment. A significant main effect for group-by-time interaction $(F=2.53, P<0.05)$ was observed, in which $\mathrm{G} 3 \mathrm{x}$ showed a higher increase than $\mathrm{G} 2 \mathrm{x}(\mathrm{G} 2 \mathrm{x}=+87.8 \%$, ES $=7.31$; $\mathrm{G} 3 \mathrm{x}=+92.2 \%$, ES=10.39).

The information regarding flexibility indicators preand post-training according to group are presented in

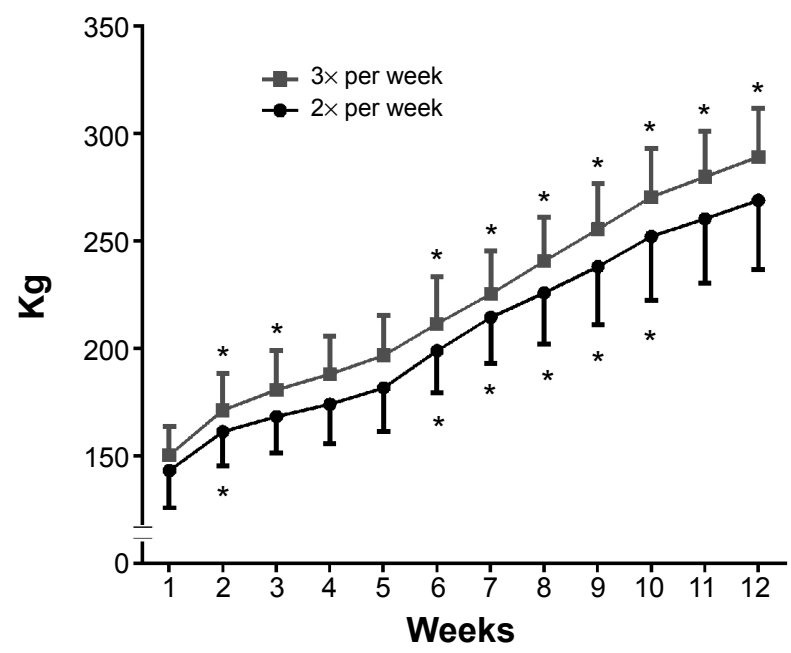

Figure 2 Weekly training load $(\mathrm{kg})$ during a resistance-training program in elderly women $(n=53)$ according to resistance-training frequency.

Notes: $* P<0.05$ vs previous week. There was a significant group-by-time interaction. Data are expressed as mean and standard deviation.
Table 2. A main effect of time $(P<0.01)$ was observed for $\mathrm{CE}(\mathrm{G} 2 \mathrm{x}=+19.1 \%, \mathrm{G} 3 \mathrm{x}=+20.0 \%)$, right hip flexion $(\mathrm{G} 2 \mathrm{x}=+14.6 \%, \mathrm{G} 3 \mathrm{x}=+15.9 \%)$, and left hip flexion $(\mathrm{G} 2 \mathrm{x}=+25.7 \%, \mathrm{G} 3 \mathrm{x}=+19.2 \%)$. Significant group-by-time interaction $(P<0.01)$ was observed only for FHF, in which G3x showed a higher increase than $\mathrm{G} 2 \mathrm{x}(+12.8 \%$, and $+3.0 \%$, respectively).

Figure 3 shows the absolute (A) and relative (B) variations from pre- to post-training on skeletal muscle mass indicators according to group. Only the main effect of time reached statistical significance $(F=22.05, P<0.001)$, with both groups having a similar increase after the 12 weeks of the RT program. The ESs for skeletal muscle mass changes were 0.21 and 0.43 for twice and thrice per week sessions, respectively.

\section{Discussion}

The main finding of the present study is that 12 weeks of RT was sufficient to increase or at least maintain flexibility in elderly women. The increases in flexibility after an RT program in older individuals have been previously reported, ${ }^{11,16-19}$ and our findings are consistent with these studies. For example, Fatouros et $\mathrm{a}^{18}$ recruited eight older men to perform 16 weeks of RT three times per week, and observed significant range-of-motion increases in knee flexion, elbow flexion, shoulder flexion, hip flexion, shoulder extension, and hip extension at study end. Gonçalves et a $1^{19}$ investigated the effect of 8 weeks of RT three times per week on the flexibility of elderly men and women, and noted an increase in shoulder extension, hip flexion, and hip extension after the intervention. Barbosa et al ${ }^{16}$ investigated the effect of 10 weeks of RT three times per week in elderly women and observed an increase in flexibility as measured by the sit-and-reach test after 10 weeks.

The exact mechanisms responsible for increased flexibility after an RT program have not yet been established in the literature and the outcomes drawn from our study do not provide mechanistic insight. Nevertheless, we can speculate on possible causes. Joint movement is related to morphological elements such as muscle, bone, and connective tissues. In particular, muscle and fascia are responsible for $\sim 41 \%$ of a joint's resistance to movement, ${ }^{27}$ suggesting that an RT-mediated reduction in passive tension and stiffness of these tissues translates into a greater range of motion. ${ }^{11}$ This hypothesis requires further study.

The novel and important feature of our study was the comparison of two versus three RT sessions per week with respect to flexibility outcomes. Results show that only FHF benefited 
Table 2 Flexibility (degrees) of different articular movements before and after 12 weeks of resistance training in elderly women

\begin{tabular}{|c|c|c|c|c|c|}
\hline Joint movement & G2x $(n=28)$ & G3x $(n=25)$ & ANOVA & $F$ & $P$-value \\
\hline \multicolumn{6}{|l|}{ Cervical flexion } \\
\hline Pre-training & $56.6 \pm 9.2$ & $57.5 \pm 11.1$ & Group & 0.12 & 0.74 \\
\hline Post-training & $57.4 \pm 10.5$ & $54.8 \pm 9.2$ & Time & 0.67 & 0.42 \\
\hline Effect size & +0.08 & -0.26 & Interaction & 2.55 & 0.12 \\
\hline \multicolumn{6}{|l|}{ Cervical extension } \\
\hline Pre-training & $55.5 \pm 8.7$ & $52.5 \pm 9.6$ & Group & 1.56 & 0.22 \\
\hline Post-training & $66.1 \pm 11.2^{*}$ & $63.0 \pm 9.4^{*}$ & Time & 63.3 & $<0.001$ \\
\hline Effect size & +1.06 & +1.11 & Interaction & $<0.01$ & 0.96 \\
\hline \multicolumn{6}{|l|}{ Frontal hip flexion } \\
\hline Pre-training & $83.1 \pm 16.3$ & $78.7 \pm 15.5$ & Group & 0.02 & 0.90 \\
\hline Post-training & $85.6 \pm 19.9$ & $88.8 \pm 20.4^{*}$ & Time & 6.79 & 0.01 \\
\hline Effect size & +0.14 & +0.56 & Interaction & 2.46 & 0.01 \\
\hline \multicolumn{6}{|l|}{ Right hip flexion } \\
\hline Pre-training & $60.9 \pm 12.1$ & $62.9 \pm 19.9$ & Group & 0.63 & 0.43 \\
\hline Post-training & $69.8 \pm 12.5^{*}$ & $72.9 \pm 14.3^{*}$ & Time & 43.72 & $<0.001$ \\
\hline Effect size & +0.72 & +0.58 & Interaction & 0.13 & 0.72 \\
\hline \multicolumn{6}{|l|}{ Left hip flexion } \\
\hline Pre-training & $61.2 \pm 13.8$ & $65.0 \pm 12.4$ & Group & $0.4 I$ & 0.53 \\
\hline Post-training & $76.9 \pm 12.0 *$ & $77.5 \pm 12.9 *$ & Time & 133.42 & $<0.001$ \\
\hline Effect size & $+\mid .21$ & +0.99 & Interaction & 1.69 & 0.20 \\
\hline
\end{tabular}

Notes: G2x, group that performed resistance training two times per week; G3x, group that performed resistance training three times per week. $* P<0.05$ vs pre-training. Data are expressed as mean and standard deviation.

Abbreviation: ANOVA, analysis of variance.

from an increased RT frequency, while all other flexibility outcomes were similar regardless of the number of weekly sessions. The fact that hip-flexion range of motion showed greater improvement when training was undertaken three times per week rather than twice per week has implications for exercise prescription. Hip flexion measures the flexibility of muscles in both the lumbar region and on the posterior thigh. These structures are highly relevant to the mobility of the torso and lower back, which has particular implications

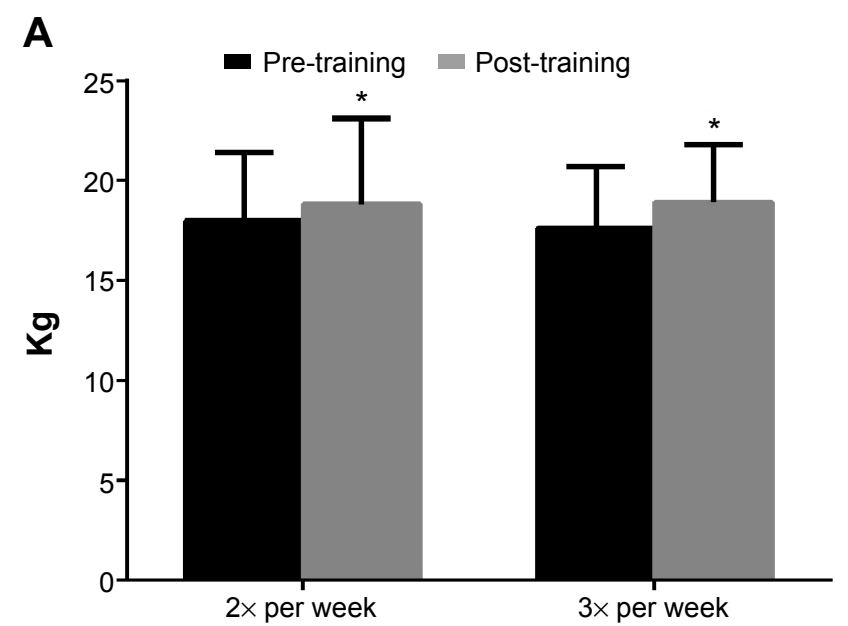

for functional capacity in the elderly.$^{28}$ Moreover, hip flexibility is a predictor of low back pain, and is strongly associated with aging. ${ }^{29}$ The muscles of the low back and the hamstrings are considered to be particularly relevant to hip mobility. ${ }^{24}$ Given that ES analysis showed the group with higher volume had a greater positive effect on skeletal muscle mass compared with the lower volume group, it is conceivable that the associated increased strength of muscles surrounding the hip may have led to a greater improvements in flexibility.

\section{B}

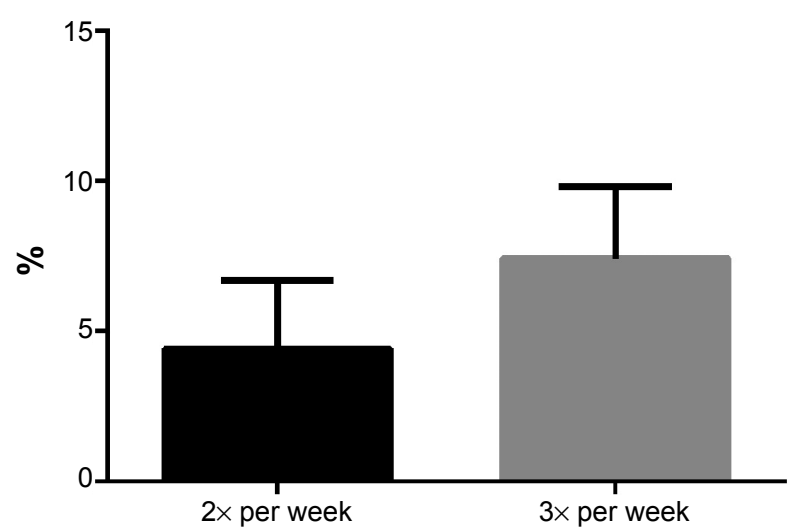

Figure 3 Absolute $(\mathbf{A})$ and relative $(\mathbf{B})$ changes between pre-training and post-training on skeletal muscle mass in elderly women ( $\mathrm{n}=53)$ according to resistance-training frequency.

Notes: $* P<0.05$ vs pre-training. Data are expressed as mean and standard deviation. 
An analysis of the weekly "training load", which refers to the load used to perform a given exercise, was adopted in this study as the muscular strength indicator. Analysis of the training load is an alternative and potentially more practical method for monitoring muscular strength changes compared with one repetition maximum test. ${ }^{30}$ Our results indicate that a greater RT frequency is associated with higher increments of specific muscle strength in the sum of exercises used ( $88 \%$ and $92 \%$, for G2x and G3x, respectively). To date, as far as we are aware, only a few studies have investigated the effects of different training frequencies in older people, ${ }^{31-33}$ with conflicting results. For example, both DiFranciscoDonoghue et al ${ }^{13}$ and Taafee et a ${ }^{33}$ showed similar increases in strength between programs with high (twice) and low (once) weekly training frequencies. Alternatively, Farinatti et $\mathrm{al}^{31}$ investigated the effects of RT once, twice, and three times per week, and observed that higher frequencies promoted greater increases in strength for certain exercises (seated dumbbell curl and knee extension) but not for others (bench press and standing calf raise). The reasons for these discrepancies are not readily apparent and require further study.

No statistically significant differences in changes in skeletal muscle mass were noted between training two versus three times a week in the present study. However, thriceweekly training showed greater absolute increases compared with the twice-weekly condition ( $7.4 \%$ vs $4.4 \%$, respectively) and the ESs were considerably larger when training three times a week as well ( 0.43 versus 0.21 , respectively). There is compelling evidence for a dose-response relationship between training volume and muscle hypertrophy. In the present study, G3x performed three sets per muscle per week while the G2x group performed two sets per muscle per week. Thus, our findings suggest a potentially meaningful benefit to increasing the volume of training for a given muscle from two to three sets per week with respect to skeletal muscle mass. Considering the relatively short duration of our study, future research is recommended to determine the extent to which such differences in skeletal muscle mass would continue or perhaps narrow over time.

Some limitations to our study need to be addressed. The data found in our study are limited to the joint movements analyzed and time of training applied. It is possible that the range of motion of these joints might continue to increase if training were to exceed 12 weeks, and the results should not be extrapolated to populations other than older women. Moreover, the absence of monitoring the physical activity and dietary intake habits is a limitation as well. On the other hand, to our knowledge, the present study is the first to have investigated the effect of different RT frequencies on flexibility in older women. Our findings indicate that RT performed at a minimum of twice per week can result in positive effects on flexibility in the elderly, reversing or slowing the aging-induced losses.

\section{Conclusion}

The results of our study suggest that 12 weeks of RT improves or at least preserves the flexibility of different joint movements in older women. In addition, the higher frequency of RT induces greater increase in FHF. Further research is warranted to determine the underlying mechanisms for these changes.

\section{Disclosure}

The authors report no conflicts of interest in this work.

\section{References}

1. Levinger I, Goodman C, Hare DL, Jerums G, Selig S. The effect of resistance training on functional capacity and quality of life in individuals with high and low numbers of metabolic risk factors. Diabetes Care. 2007; 30(9):2205-2210.

2. Vale RG, Barreto AC, Novaes JS, Dantas EH. Efeitos do treinamento resistido na força máxima, na flexibilidade e na autonomia funcional de mulheres idosas [Effect of resistive training on the maximum strength, flexibility and functional autonomy of elderly women]. Revista Brasileira de Cineantropometria e Desempenho Humano. 2006;8(4):52-58. Portuguese.

3. Gehlsen GM, Whaley MH. Falls in the elderly: Part II, Balance, strength, and flexibility. Arch Phys Med Rehabil. 1990;71(10):739-741.

4. Batista FS, Gomes GA, D'Elboux MJ, et al. Relationship between lower-limb muscle strength and functional independence among elderly people according to frailty criteria: a cross-sectional study. Sao Paulo Med J. 2014;132(5):282-289.

5. Clark BC, Manini TM. Functional consequences of sarcopenia and dynapenia in the elderly. Curr Opin Clin Nutr Metab Care. 2010;13(3): 271-276.

6. Cunningham DA, Paterson DH, Himann JE, Rechnitzer PA. Determinants of independence in the elderly. Can J Appl Physiol. 1993; 18(3):243-254.

7. American College of Sports Medicine, Chodzko-Zajko WJ, Proctor DN, et al. American College of Sports Medicine position stand. Exercise and physical activity for older adults. Med Sci Sports Exerc. 2009; 41(7):1510-1530.

8. Barbosa AR, Souza JM, Lebrão ML, Laurenti R, Marucci Mde F. Functional limitations of Brazilian elderly by age and gender differences: data from SABE Survey. Cad Saude Publica. 2005;21(4):1177-1185.

9. Gosselin LE, Adams C, Cotter TA, McCormick RJ, Thomas DP. Effect of exercise training on passive stiffness in locomotor skeletal muscle: role of extracellular matrix. J Appl Physiol (1985). 1998;85(3):1011-1016.

10. Kubo K, Kanehisa H, Miyatani M, Tachi M, Fukunaga T. Effect of low-load resistance training on the tendon properties in middle-aged and elderly women. Acta Physiol Scand. 2003;178(1):25-32.

11. Correia MA, Menêses AL, Lima AH, Cavalcante BR, Ritti-Dias RM. Efeito do treinamento de força na flexibilidade: uma revisão sistemática [Effect of strength training on flexibility: a systematic review]. Atividade Física e Saúde. 2014;19(1):3-11. Portuguese.

12. American College of Sports Medicine. American College of Sports Medicine position stand. Progression models in resistance training for healthy adults. Med Sci Sports Exerc. 2009;41(3):687-708. 
13. Garber CE, Blissmer B, Deschenes MR, et al; American College of Sports Medicine. American College of Sports Medicine position stand. Quantity and quality of exercise for developing and maintaining cardiorespiratory, musculoskeletal, and neuromotor fitness in apparently healthy adults: guidance for prescribing exercise. Med Sci Sports Exerc. 2011;43(7):1334-1359.

14. Cadore EL, Pinto RS, Bottaro M, Izquierdo M. Strength and endurance training prescription in healthy and frail elderly. Aging Dis. 2014; 5(3):183-195.

15. Cyrino ES, Oliveira AR, Leite JC, et al. Comportamento da flexibilidade após 10 semanas de treinamento com pesos [Flexibility behavior after 10 weeks of resistance training]. Rev Bras Med Esporte. 2004;10(4): 233-237. Portuguese.

16. Barbosa AR, Santarém JM, Filho WJ, Marucci Mde F. Effects of resistance training on the sit-and-reach test in elderly women. J Strength Cond Res. 2002;16(1):14-18

17. Fatouros IG, Kambas A, Katrabasas I, et al. Resistance training and detraining effects on flexibility performance in the elderly are intensitydependent. J Strength Cond Res. 2006;20(3):634-642.

18. Fatouros IG, Taxildaris K, Tokmakidis SP, et al. The effects of strength training, cardiovascular training and their combination on flexibility of inactive older adults. Int J Sports Med. 2002;23(2):112-119.

19. Gonçalves R, Gurjão AL, Gobbi S. Efeitos de oito semanas do treinamento de força na flexibilidade de idosos. [Effects of eight weeks strength training on flexibility in older adults]. Revista Brasileira de Cineantropometria e Desempenho Humano. 2007;9(2):145-153.

20. Morton SK, Whitehead JR, Brinkert RH, Caine DJ. Resistance training vs static stretching: effects on flexibility and strength. J Strength Cond Res. 2011;25(12):3391-3398.

21. Krieger JW. Single vs multiple sets of resistance exercise for muscle hypertrophy: a meta-analysis. J Strength Cond Res. 2010;24(4): 1150-1159.
22. Krieger JW. Single versus multiple sets of resistance exercise: a metaregression. J Strength Cond Res. 2009;23(6):1890-1901.

23. Kim J, Wang Z, Heymsfield SB, Baumgartner RN, Gallagher D. Totalbody skeletal muscle mass: estimation by a new dual-energy X-ray absorptiometry method. Am J Clin Nutr. 2002;76(2):378-383.

24. Phillips WT, Haskell WL. "Muscular fitness" - easing the burden of disability for elderly adults. J Aging Phys Act. 1995;3:261-289.

25. Achour Júnior A. Avaliando a flexibilidade: Flexímeter [Evaluating the flexibility: fleximeter]. Londrina: Midiograf; 1997. Portuguese.

26. Cohen J. Statistical Power Analysis for the Behavioral Sciences. 2nd ed Hillsdale, NJ: Lawrence Erlbaum; 1988.

27. Johns RJ, Wright V. Relative importance of various tissues in joint stiffness. J Appl Physiol. 1962;17:824-828.

28. Rider RA, Daly J. Effects of flexibility training on enhancing spinal mobility in older women. J Sports Med Phys Fitness. 1991;31(2): 213-217.

29. Biering-Sørensen F. Physical measurements as risk indicators for low-back trouble over a one-year period. Spine (Phila Pa 1976). 1984; 9(2):106-119.

30. Ribeiro AS, Avelar A, Schoenfeld BJ, et al. Analysis of the training load during a hypertrophy-type resistance training programme in men and women. Eur J Sport Sci. 2014. Epub July 28.

31. Farinatti PT, Geraldes AA, Bottaro MF, Lima MV, Albuquerque RB, Fleck SJ. Effects of different resistance training frequencies on the muscle strength and functional performance of active women older than 60 years. J Strength Cond Res. 2013;27(8):2225-2234.

32. DiFrancisco-Donoghue J, Werner W, Douris PC. Comparison of onceweekly and twice-weekly strength training in older adults. Br J Sports Med. 2007;41(1):19-22.

33. Taaffe DR, Duret C, Wheeler S, Marcus R. Once-weekly resistance exercise improves muscle strength and neuromuscular performance in older adults. J Am Geriatr Soc. 1999;47(10):1208-1214.
Clinical Interventions in Aging

\section{Publish your work in this journal}

Clinical Interventions in Aging is an international, peer-reviewed journal focusing on evidence-based reports on the value or lack thereof of treatments intended to prevent or delay the onset of maladaptive correlates of aging in human beings. This journal is indexed on PubMed Central, MedLine,

\section{Dovepress}

CAS, Scopus and the Elsevier Bibliographic databases. The manuscript management system is completely online and includes a very quick and fair peer-review system, which is all easy to use. Visit http://www.dovepress. com/testimonials.php to read real quotes from published authors. 